\title{
Feline Coronavirus Type II Strains 79-1683 and 79-1146 Originate from a Double Recombination between Feline Coronavirus Type I and Canine Coronavirus
}

\author{
ARNOLD A. P. M. HERREWEGH, INGRID SMEENK, MARIAN C. HORZINEK, \\ PETER J. M. ROTTIER, AND RAOUL J. DE GROOT* \\ Virology Unit, Department of Infectious Diseases and Immunology, Faculty of \\ Veterinary Medicine, Utrecht University, Utrecht, The Netherlands
}

Received 5 November 1997/Accepted 10 February 1998

\begin{abstract}
Recent evidence suggests that the type II feline coronavirus (FCoV) strains 79-1146 and 79-1683 have arisen from a homologous RNA recombination event between FCoV type I and canine coronavirus (CCV). In both cases, the template switch apparently took place between the $S$ and $M$ genes, giving rise to recombinant viruses which encode a CCV-like S protein and the M, N, 7a, and 7b proteins of FCoV type I (K. Motowaka, T. Hohdatsu, H. Hashimoto, and H. Koyama, Microbiol. Immunol. 40:425-433, 1996; H. Vennema, A. Poland, K. Floyd Hawkins, and N. C. Pedersen, Feline Pract. 23:40-44, 1995). In the present study, we have looked for additional FCoV-CCV recombination sites. Four regions in the pol gene were selected for comparative sequence analysis of the type II FCoV strains 79-1683 and 79-1146, the type I FCoV strains TN406 and UCD1, the CCV strain K378, and the TGEV strain Purdue. Our data show that the type II FCoVs have arisen from double recombination events: additional crossover sites were mapped in the ORF1ab frameshifting region of strain 79-1683 and in the $5^{\prime}$ half of ORF1b of strain 79-1146.
\end{abstract}

Coronaviruses, pathogens of mammals and birds, are enveloped RNA viruses with a nonsegmented, positive-stranded genome that is 27 to $32 \mathrm{~kb}$ in length (for a review, see reference 41). The 5' two-thirds of the genome is occupied by open reading frames (ORFs) 1a and 1b, the expression of which yields large polyproteins from which the viral replicase is derived. Downstream of ORF1b, there are 8 to 10 smaller ORFs which are expressed through subgenomic mRNAs. These code for the structural proteins $\mathrm{S}, \mathrm{E}, \mathrm{M}$, and $\mathrm{N}$ and for a number of presumptive nonstructural proteins (reviewed in reference 32) (for a schematic representation of a coronavirus genome, see Fig. 1).

One of the most intriguing aspects of coronavirus replication is the occurrence of high-frequency homologous RNA recombination (30, 33; for reviews, see references 28 and 29). This process is thought to be mediated by a "copy-choice" mechanism $(7,24,33)$. In this model, the RNA-dependent RNA polymerase together with the nascent $\mathrm{cRNA}$ product dissociates from the original template, reassociates with another template at the identical or nearly identical position, and subsequently recommences RNA synthesis. Template switching occurs randomly $(1,44)$ and, in the case of mouse hepatitis virus, at an estimated frequency of approximately $1 \%$ per 1,300 nucleotides, i.e., $25 \%$ for the entire $32-\mathrm{kb}$ genome (2). Homologous recombination not only allows the rapid exchange of beneficial mutations but also may serve as a correction mechanism counteracting Muller's ratchet $(6,28)$. Recombination of coronavirus genomes has been observed in tissue culture $(30,33)$, in experimentally infected animals (23), and in embryonated eggs (26). In the case of infectious bronchitis virus, there is evidence for homologous recombination occurring in

\footnotetext{
* Corresponding author. Mailing address: Virology Unit, Department of Infectious Diseases and Immunology, Faculty of Veterinary Medicine, Utrecht University, POB 80.165, 3508 TD Utrecht, The Netherlands. Phone: 31-30-2532460. Fax: 31-30-2536723. E-mail: R .Groot@vetmic.dgk.ruu.nl.
}

the field $(22,27,47)$. Recent findings suggest that homologous RNA recombination may also be an important factor in the evolution of feline coronaviruses (FCoVs) $(16,37,46)$.

Together with porcine transmissible gastroenteritis virus (TGEV), canine coronavirus (CCV), and human coronavirus (HCV) 229E, FCoVs form a separate cluster within the genus Coronavirus. They are commonly associated with mild enteric infections but are also associated with feline infectious peritonitis, a fatal immune-mediated disease of both domestic and wild felidae (for a review, see reference 8). Two FCoV serotypes exist; they can be distinguished by an in vitro virus neutralization assay using either type-specific feline sera (39) or monoclonal antisera directed against the S protein (18-20). The prevalence of these serotypes has not been studied exten-

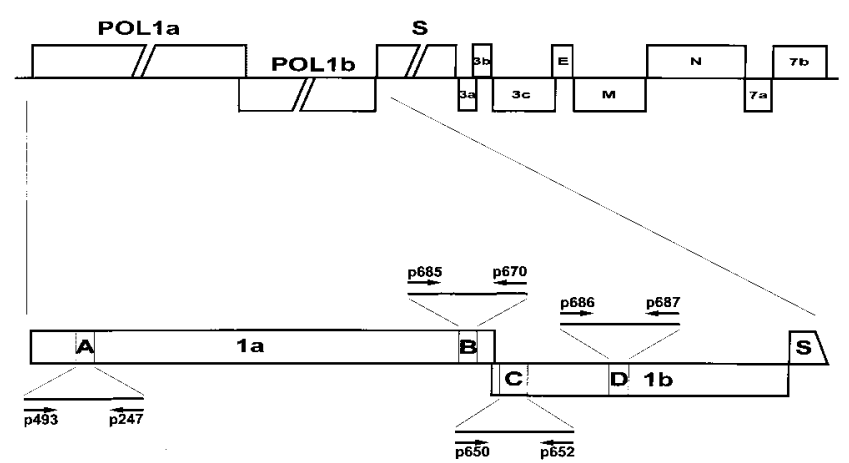

FIG. 1. Genomic organization of FCoV and an outline of the strategies used for the amplification of specific regions in the polymerase genes. (Upper panel) Schematic representation of the genome of FCoV strain 79-1146 with the various genes represented by boxes. The genes for the polymerase (POL1a, POL1b), the structural proteins $\mathrm{S}, \mathrm{M}, \mathrm{E}$, and $\mathrm{N}$, and the presumptive nonstructural proteins $3 \mathrm{a}, 3 \mathrm{~b}, 3 \mathrm{c}, 7 \mathrm{a}$, and $7 \mathrm{~b}$ are indicated. (Lower panel) Schematic presentation of ORF1a and ORF1b, indicating the locations of regions A through D. The positions and polarities of the oligonucleotide primers used for RT-PCR amplification and sequence analysis are indicated. 


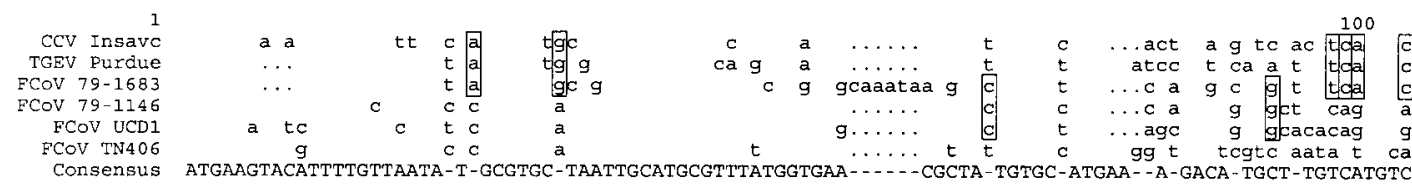

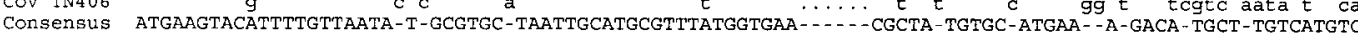
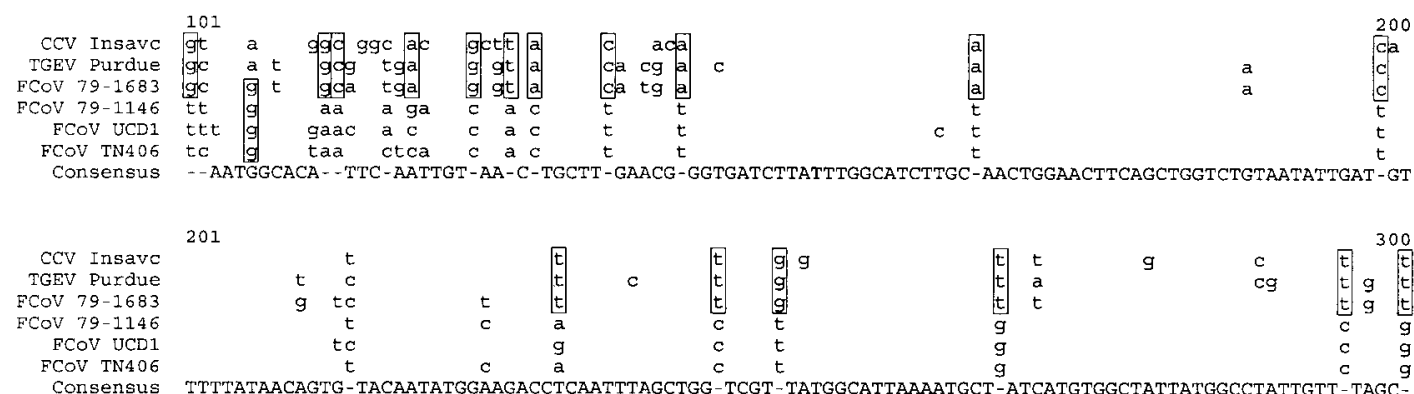

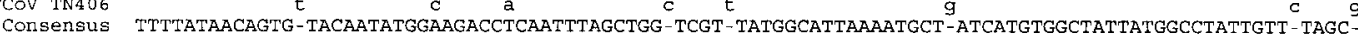
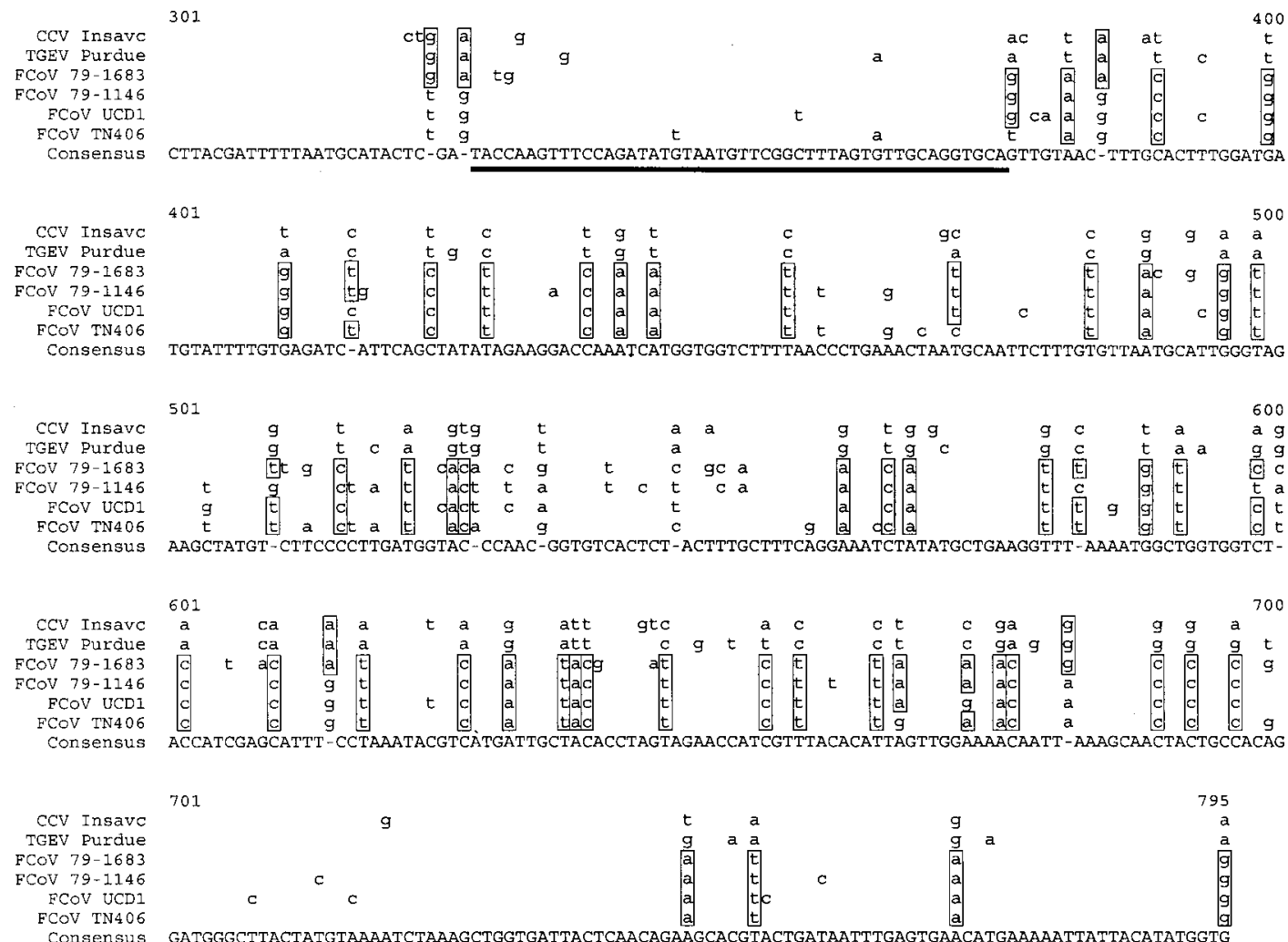

FIG. 2. Comparative sequence analysis of the M gene. An alignment is shown of the nucleotide sequences of the FCoV type I strains UCD1 and TN406 (37), the FCoV type II strains 79-1683 (15, 37) and 79-1146 (45), the CCV strain Insavc-1 (21), and the TGEV strain Purdue (40). Alignments were performed by using the PILEUP program (University of Wisconsin) (17). Only the nucleotides differing from the consensus sequence are depicted. Those nucleotides of the 79-1683 sequence which are identical to those of the CCV and TGEV sequences or to residues of at least two other FCoV strains are boxed. Template switching between the CCV and FCoV type I genomes apparently occurred in the region formed by nt 327 through 376 (underlined).

sively but according to a recent sero-survey, type II FCoVs may account for 20 to $30 \%$ of the feline infectious peritonitis cases in Japan (18).

Interestingly, serologic studies suggested that the type II FCoVs are more closely related to CCV than to type I strains; i.e., immunodominant neutralization epitopes shared by the $\mathrm{S}$ proteins of $\mathrm{CCV}$ and FCoV type II are absent in the $\mathrm{S}$ protein of FCoV type I. Puzzlingly, however, comparative sequence analysis of the ORF7a-ORF7b region (Fig. 1) revealed that in the $3^{\prime}$-most $1.5 \mathrm{~kb}$ of the genome, type I and II FCoVs are more closely related to each other than they are to CCV (16). These seemingly conflicting observations could be reconciled upon genetic comparison of the region between ORF1b and ORF7a. Whereas the type I and II viruses are also closely related in the genes encoding $\mathrm{M}$ and $\mathrm{N}$ proteins, the $\mathrm{S}$ genes are markedly different $(36,37,46)$. In fact, the $S$ proteins of the type II FCoV strains 79-1146 and 79-1683 bear a much greater amino acid sequence identity to those of CCV (91\%) and TGEV $(81 \%)$ than to the $\mathrm{S}$ proteins of the type I strains TN406, UCD1, and Ku2 (46\%) $(36,49)$. The data strongly 


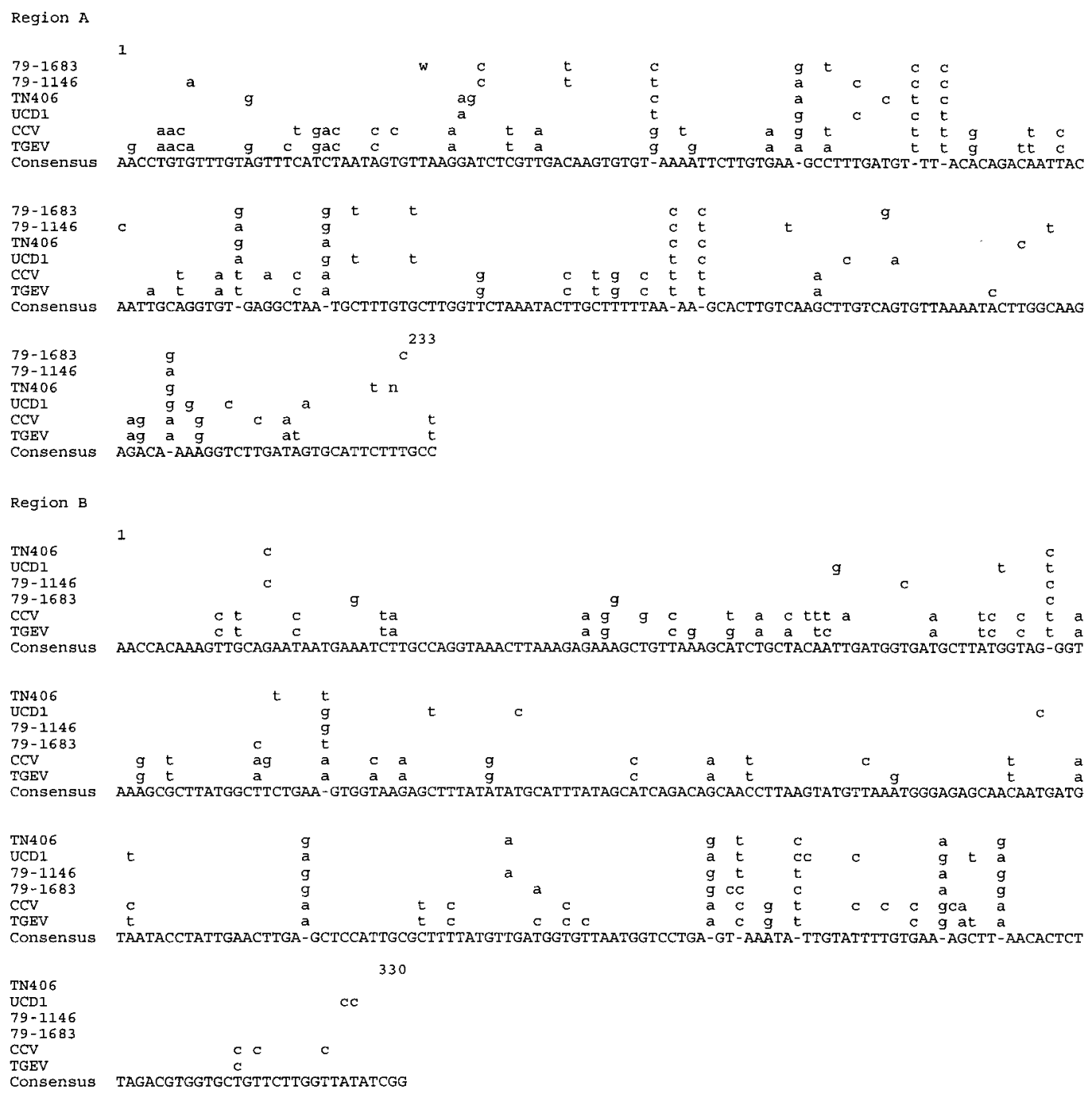

FIG. 3. Comparative sequence analysis of genomic regions A through D. Alignments were made by using the PILEUP program (University of Wisconsin), which scores identity between every possible pair (17). Alignment of the nucleotide sequences of regions A through D, as determined for the FCoV type I strains UCD1 and TN406, the FCoV type II strains 79-1683 and 79-1146, the CCV strain K378, and the TGEV strain Purdue (11), is shown. Only those nucleotides differing from the consensus sequence are depicted. $\mathrm{n}, \mathrm{r}$, and $\mathrm{w}$ represent nucleotides $\mathrm{A} / \mathrm{C} / \mathrm{G} / \mathrm{T}, \mathrm{A} / \mathrm{G}$, and $\mathrm{A} / \mathrm{T}$, respectively.

suggest that the type II FCoV strains have arisen from a homologous RNA recombination event between $\mathrm{CCV}$ and a type I FCoV $(16,37,46)$. In the case of the FCoV type II strain 79-1146, the template switch has occurred within the E gene (44a). Data published by Motokawa et al. (37) indicated that for FCoV type II strain 79-1683, the template switch also took place between the $\mathrm{S}$ and $\mathrm{M}$ genes. From comparative sequence analysis of the ORF3a to ORF3c region (15) and a reevaluation of published data (37), it now appears that the crossover occurred in the $\mathrm{M}$ gene in the region formed by nucleotides (nt) 327 to 376 (Fig. 2). The fact that the template switch occurred at different sites in strains 79-1146 and 79-1683 suggests that they have arisen from separate recombination events.

One important question remaining was whether the type II strains had originated from single crossovers or from multiple template switches. Here, we have investigated the presence of additional switch sites in the pol genes. To this end, four regions in ORF1a and ORF1b, designated A through D (Fig. 1), were chosen for comparative sequence analysis of the type II FCoV strains 79-1146 and 79-1683, the type I FCoV strains Black and UCD1, the CCV strain K378, and the TGEV strain
Purdue (11). The FCoV and CCV strains were grown in fcwf-D cells, and viral RNA was isolated from infected cells as described previously (9). Oligonucleotide primers (Table 1) were designed after regions conserved in the pol genes of TGEV

TABLE 1. Oligonucleotide primers used for RT-PCR and cycle sequence analysis

\begin{tabular}{llcl}
\hline Primer & \multicolumn{1}{c}{ Sequence $\left(5^{\prime}\right.$ to $\left.3^{\prime}\right)$} & ${\text { Position }(\mathrm{nt})^{a}}^{a}$ & Orientation \\
\hline p247 & CCGTTGTGGTGTCACATTAAC & $1895-1875$ & Antisense \\
p493 & GTAGTAGCATCACTCTGCACTTC & $1575-1597$ & Sense \\
p650 & TGGTGCTGTTGCTGAGCATGA & $12574-12594$ & Sense \\
p652 & ACAACTACTGGTACACCATCAA & $13323-13302$ & Antisense \\
p670 & TCAGTGGTTTACCAGCTTGCA & $11920-11899$ & Antisense \\
p685 & GCCCTTGAGTATAACTTGTGAG & $11531-11552$ & Sense \\
p686 & GAAACTGTGAAAGCTAAGGAGG & $15500-15521$ & Sense \\
p687 & ACACAATGAGATTTACCGCTACC & $15972-15950$ & Antisense \\
\hline
\end{tabular}

${ }^{a}$ Numerical position on the genome of TGEV strain Purdue as counted from the first nucleotide of the sequence deposited under GenBank accession no. Z34093 (11). 
Region C

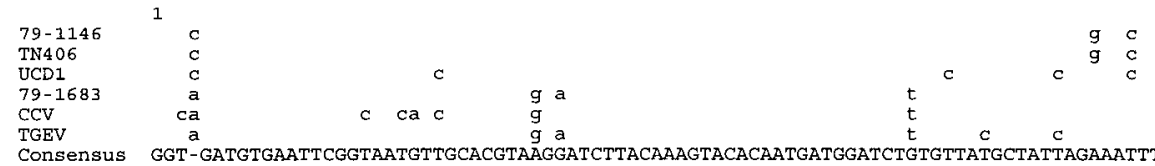

Consensus GGT-GATGTGAATTCGGTAATGTTGCACGTAAGGATCTTACAAAGTACACAATGATGGATCTGTGTTATGCTATTAGAAATTTTGATGAAAAGAACTGTG

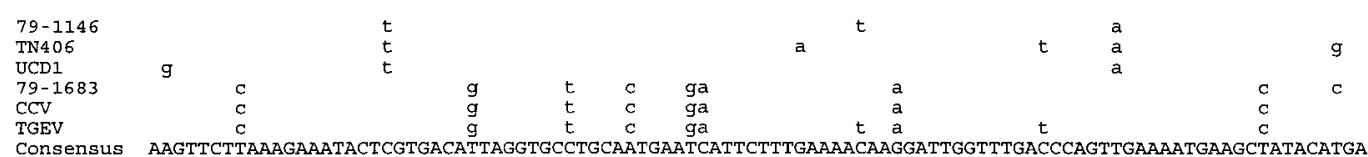

Consensus AAGTTCTTAAAGAAATACTCGTGACATTAGGTGCCTGCAATGAATCATTCTTTGAAAACAAGGATTGGTTTGACCCAGTTGAAAATGAAGCTATACATGA

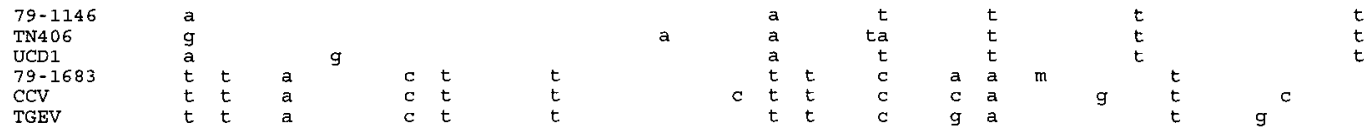

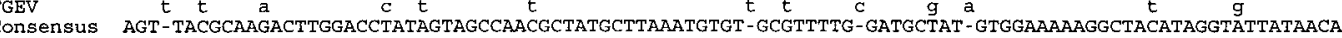

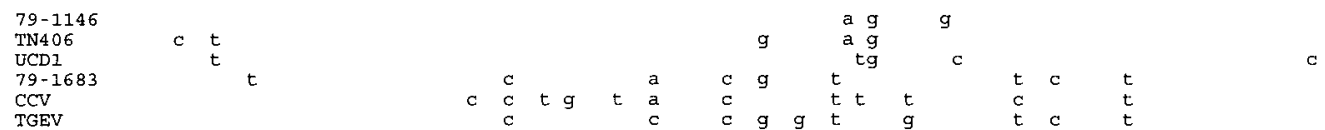

Consensus CTTGACAACCAAGATCTTAATGGCAATTTTTACGATTTCGGTGATTTTGTAAAAACAGCTCCAGGTTTTGGATGTGCTTGCGTTACATCATATTATTCTT

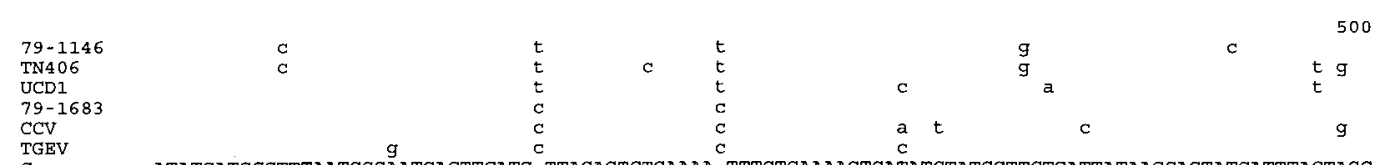

Region D
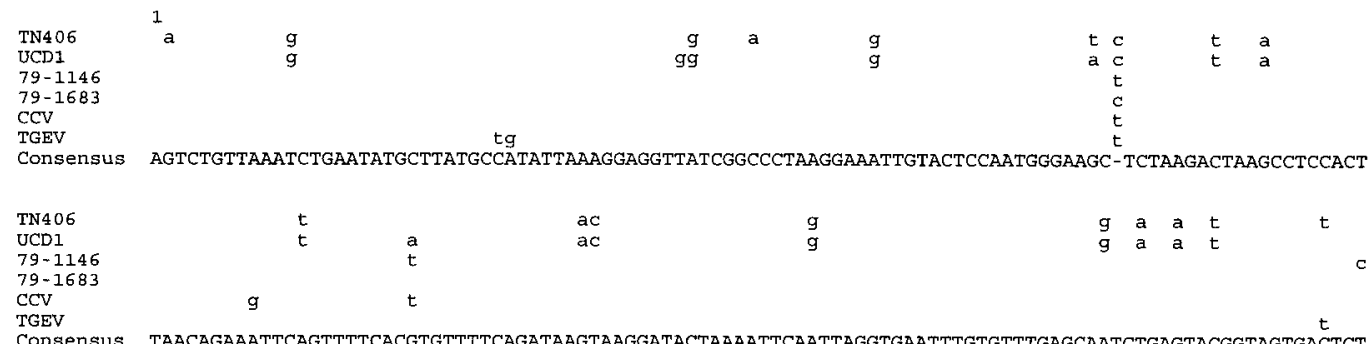

Consensus TAACAGAAATTCAGTTTTCACGTGTTTTCAGATAAGTAAGGATACTAAAATTCAATTAGGTGAATTTGTGTTTGAGCAATCTGAGTACGGTAGTGACTCT

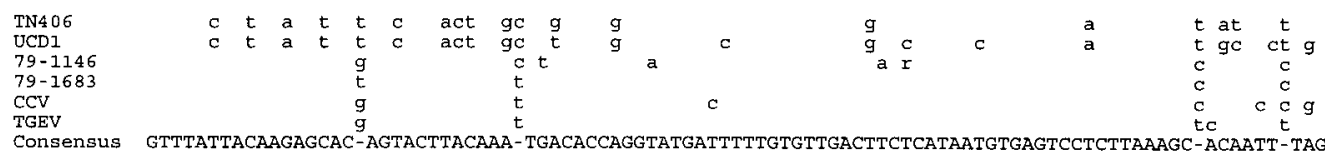

Consensus GTTTATTACAAGAGCAC-AGTACTTACAAA-TGACACCAGGTATGATTTTTGTGTTGACTTCTCATAATGTGAGTCCTCTTAAAGC-ACAATT-TAGTCA

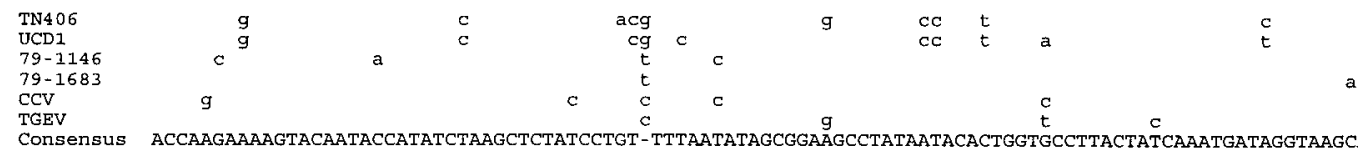

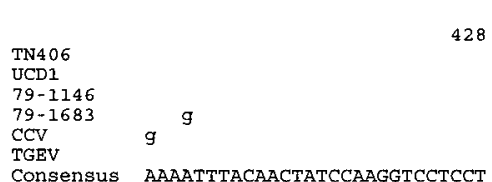

FIG. 3-Continued.

strain Purdue (11) and HCV strain 229E (13), and reverse transcriptase PCR (RT-PCR) was performed as described previously (16) (for a schematic outline, see Fig. 1). In all cases, PCR products of the anticipated size were obtained (data not shown). These were purified from agarose gels and subjected to cycle sequence analysis using the AmpliCycle sequencing kit
(Perkin Elmer/Roche, Branchburg, N.J.) in accordance with the instructions of the manufacturer. For each region, the nucleotide sequence was determined in both orientations on at least two independently generated RT-PCR products. Computer-assisted nucleotide sequence alignment was performed by using the PILEUP program (Genetics Computer Group 

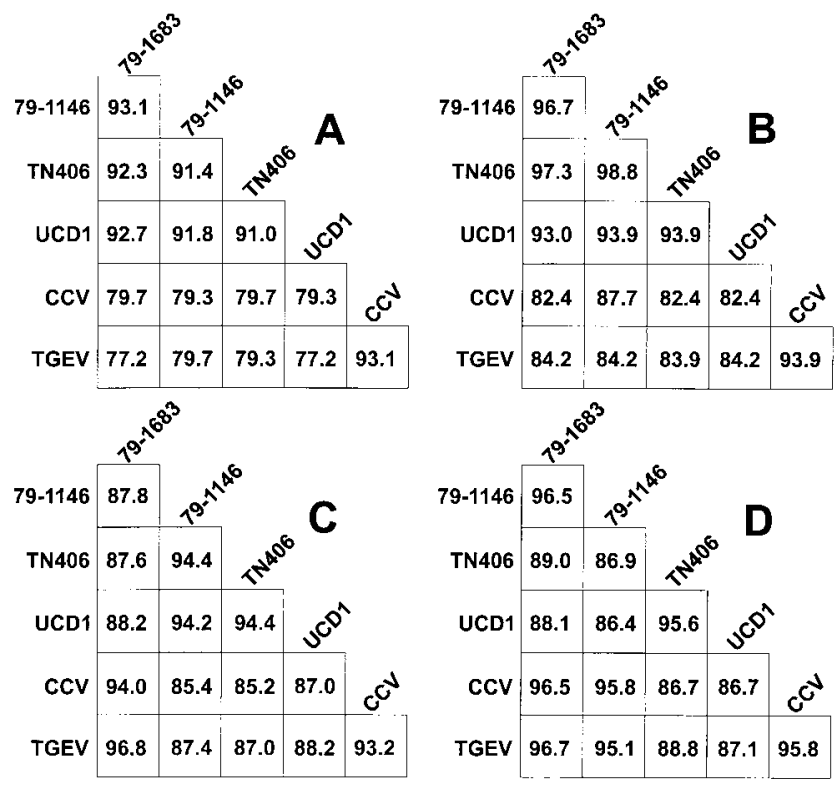

FIG. 4. Percentages of nucleotide sequence identity between polymerase regions A to D of the FCoV type I and II strains, CCV, and TGEV.

Wisconsin Package) (17), and the similarity scores were used to create dendrograms by the unweighted pair-group method using arithmetic averages as described by Sneath and Sokal (42).

The results are presented in Fig. 3 to 5. In region A, which is located at the $5^{\prime}$ end of ORF1a (corresponding to nt 1575 to 1895 of TGEV strain Purdue) (11), the type II FCoV strains $79-1146$ and $79-1683$ have 91.4 to $92.7 \%$ sequence identity with the type I strains Black and UCD1, compared with only 77.2 to $79.7 \%$ with $\mathrm{CCV}$ and TGEV. In this region, the TGEV and CCV sequences are $93.1 \%$ identical (Fig. 3 and 4). Consistently, in a dendrogram schematically displaying the nucleotide sequence identity between the different viruses, the FCoV strains form a separate cluster distinct from that of CCV and TGEV (Fig. 5). A similar situation exists in region B, located at the $3^{\prime}$ end of POL1a (corresponding to nt 11531 to 11920 of TGEV strain Purdue). Here, the sequence identity among the FCoV strains ranges between 93.0 and $98.8 \%$, whereas sequence identity with CCV and TGEV varies between 82.4 and 87.7\% (Fig. 4). Again, CCV and TGEV cluster, displaying 93.9\% sequence identity in this region. In contrast, in region $\mathrm{C}$ at the $5^{\prime}$ end of ORF1b (corresponding to nt 12574 to 13323 of TGEV strain Purdue), FCoV strain 79-1683 is more closely related to $\mathrm{CCV}$ and TGEV, with sequence identities of 94.0 and $96.8 \%$, respectively (Fig. 3 and 4 ) than to the type I FCoVs. The other type II strain, 79-1146, however, still clusters with the type I FCoV strains. Finally, in region D, located in the middle of ORF1b (corresponding to nt 15500 to 15972 of TGEV strain Purdue), both type II FCoV strains are more closely related to TGEV and CCV, with sequence identities ranging from 95.1 to $96.7 \%$, than to type I FCoVs, with sequence identities of 86.4 to $89.0 \%$. The type I FCoV strains have a sequence identity of $95.6 \%$ in region D (Fig. 4).

Our findings provide further evidence that the type II FCoV strains 79-1146 and 79-1683 are recombinant viruses and suggest that they actually originated from double RNA recombination events. In the case of strain 79-1146, an additional template switch apparently occurred in ORF1b, between regions $\mathrm{C}$ and $\mathrm{D}$, whereas for strain 79-1683, switching took place
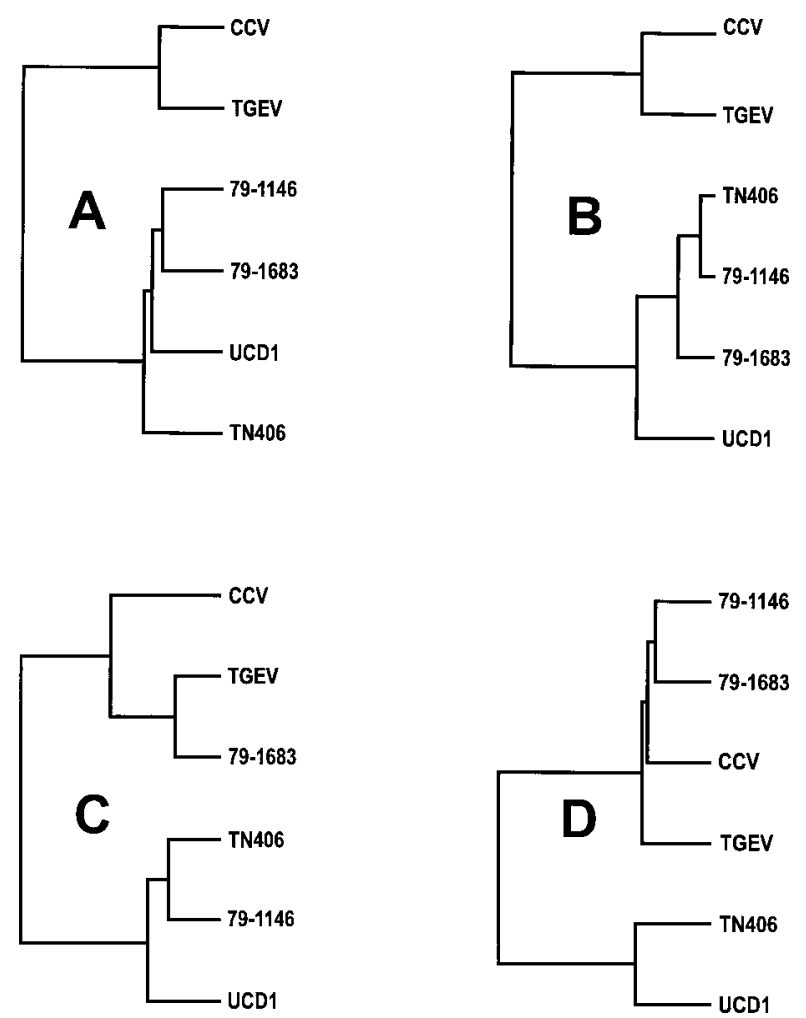

FIG. 5. Dendrograms schematically representing the sequence identity between polymerase regions A to D of FCoV type I and II strains, CCV, and TGEV. The similarity scores as calculated by the PILEUP program were used to create dendrograms by the unweighted pair-group method using arithmetic averages as described by Sneath and Sokal (42). The distances along the vertical axis are proportional to the number of nucleotide differences.

further upstream, in the ORF1ab frameshifting region between sites $\mathrm{B}$ and $\mathrm{C}$ (Fig. 6). The fact that the template switches in the pol gene occurred at different sites again is consistent with strains 79-1146 and 79-1683 having originated independently. FCoV type I and CCV are the presumptive parental viruses $(37,46)$, but it is not known in which host species the recombination took place. Under experimental conditions, cats can be infected with $\operatorname{CCV}(3,34,35,43)$. Whether CCV and FCoV readily cross species barriers in the field remains to be determined.

$79-1683$

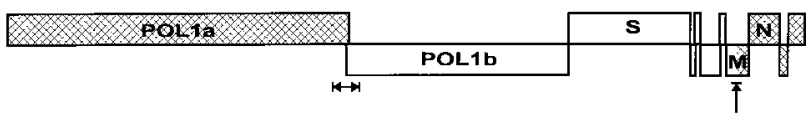

$79-1146$

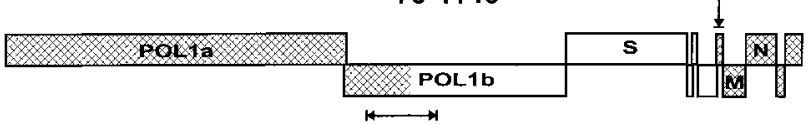

FIG. 6. Recombination patterns of the FCoV strains 79-1146 and 79-1683. The schematic representations of the two virus genomes are as detailed in Fig. 1. Hatched boxes indicate parts of the FCoV type II genome thought to have originated from FCoV type I. Open boxes represent sequences apparently obtained from CCV. The regions where the template switches have taken place are underlined. 
The recombination events from which the type II viruses resulted can be explained by two models. In the most simple scenario, the recombination may involve only two parental virus strains, with RNA replication initiating on a type I FCoV template of either negative or positive polarity (31) and then switching of the polymerase-nascent cRNA complex to a CCV template, followed by a switchback. Alternatively, a more complicated scheme can be envisaged; in this scheme, a CCVFCoV hybrid, arisen from a single template switch, spreads into the cat population and in turn engages in additional recombination events with another type I FCoV strain(s). Recent evidence suggests that FCoV type I viruses cause chronic enteric infections that may last for at least 7 months (14). Conceivably, persistence of FCoV would raise the odds of occurrence of double infections.

In general, a recombinant virus, to emerge and establish itself in the field, needs not just to be viable but to have a selective advantage. Thus, the uptake of CCV sequences by the type II FCoVs may have led to increased viral fitness as compared to the type I FCoV. Which of the acquired genes provided the selective advantage is as yet unknown. Studies of other coronaviruses have shown that the $\mathrm{S}$ protein plays a crucial role in eliciting protective immunity $(4,5,12,25,38$, 48). Moreover, genetic characterization of FCoVs isolated from persistently infected cats suggested that $\mathrm{S}$ is subject to antigenic drift, implying that this protein is a prime target for the immune system during chronic infection. From this work, it also appears that FCoV-infected cats develop resistance against FCoV superinfection, at least by antigenically closely related strains (14). Perhaps the acquisition of a CCV spike by a type I FCoV resulted in an antigenic shift, allowing the recombinant virus to escape host and/or herd immunity. However, it is also possible that the acquired CCV sequences provided a growth advantage. As compared to the type I FCoVs, type II FCoVs replicate far more efficiently in tissue culture cells and produce 50- to 100-fold-higher titers of extracellular virus (39).

It is of equal interest that both type II strains have retained FCoV sequences from the $5^{\prime}$ and $3^{\prime}$ ends of the FCoV type I genome. One interpretation is that these FCoV sequences are required for efficient replication in the cat and that selection against recombinant viruses, arisen from a single template switch, occurs. It is particularly intriguing that both strains 79-1146 and 79-1683 have retained the FCoV type I ORF1a. The POL1a polyprotein gives rise to a number of cleavage products of unknown function (reviewed in reference 10), some of which may be involved in specific virus-host interactions. Further genetic characterization of type II FCoVs and mapping of recombination sites will provide more insight into these issues and increase our understanding of coronavirus pathobiology and evolution.

We thank K. Motokawa for sharing the nucleotide sequences of the $\mathrm{M}$ and $\mathrm{N}$ genes of FCoV strains UCD1 and TN406 and H. Vennema for sharing unpublished data and for advice and helpful suggestions.

R. J. de Groot was supported by a fellowship from the Royal Netherlands Academy of Arts and Sciences.

\section{REFERENCES}

1. Banner, L. R., and M. M. C. Lai. 1991. Random nature of coronavirus RNA recombination in the absence of selection pressure. Virology 185:441-445.

2. Baric, R. S., K. F. Fu, M. C. Schaad, and S. A. Stohlman. 1990. Establishing a genetic recombination map of murine coronavirus strain A59 complementation groups. Virology 177:646-656.

3. Barlough, J. E., C. A. Stoddart, G. P. Sorresso, R. H. Jacobson, and F. W. Scott. 1984. Experimental inoculation of cats with canine coronavirus and subsequent challenge with feline infectious peritonitis virus. Lab. Anim. Sci. 34:592-597.
4. Brown, C. S., S. Welling-Wester, M. Feijlbrief, J. W. M. van Lent, and W. J. M. Spaan. 1994. Chimeric parvovirus B19 capsids for the presentation of foreign epitopes. Virology 198:477-488.

5. Cavanagh, D., P. J. Davis, J. H. Darbyshire, and R. W. Peters. 1986. Coronavirus IBV: virus retaining spike glycopolypeptide S2 but not S1 is unable to induce virus-neutralizing or haemagglutination-inhibiting antibody or induce chicken tracheal protection. J. Gen. Virol. 67:1435-1442.

6. Chao, L. 1990. Fitness of RNA virus decreased by Muller's ratchet. Nature 348:454-455.

7. Cooper, P. D., S. Steiner-Pryor, P. D. Scotti, and D. Delong. 1974. On the nature of poliovirus genetic recombinants. J. Gen. Virol. 23:41-49.

8. de Groot, R. J., and M. C. Horzinek. 1995. Feline infectious peritonitis, p. 293-309. In S. G. Siddell (ed.), The Coronaviridae. Plenum Press, New York, N.Y.

9. de Groot, R. J., R. J. Ter Haar, M. C. Horzinek, and B. A. M. Van der Zeijst. 1987. Intracellular RNAs of the feline infectious peritonitis coronavirus strain 79-1146. J. Gen. Virol. 68:995-1002.

10. de Vries, A. A. F., M. C. Horzinek, P. J. M. Rottier, and R. J. de Groot. 1997. The genome organisation of the Nidovirales: similarities and differences among arteri-, toro- and coronaviruses. Semin. Virol. 8:33-48.

11. Eleouet, J., D. Rasschaert, P. Lambert, L. Levy, P. Vende, and H. Laude. 1995. Complete sequence (20 kilobases) of the polyprotein-encoding gene 1 of transmissible gastroenteritis virus. Virology 206:817-822.

12. Hasony, H. J., and M. R. Macnaughton. 1981. Antigenicity of mouse hepatitis virus strain 3 subcomponents in C57 strain mice. Arch. Virol. 69:33-41.

13. Herold, J., T. Raabe, B. Schelle-Prinz, and S. G. Siddell. 1993. Nucleotide sequence of the human coronavirus 229E RNA polymerase locus. Virology 195:680-691.

14. Herrewegh, A. A. P. M., M. Mähler, H. J. Hedrich, B. L. Haagmans, H. F. Egberink, M. C. Horzinek, P. J. M. Rottier, and R. J. de Groot. 1997. Persistence and evolution of feline coronavirus in a closed cat-breeding colony. Virology 234:349-363.

15. Herrewegh, A. A. P. M., A. Veldkamp, E. de Rooij, H. Vennema, and R. J. de Groot. 1997. Nucleotide sequence of the 3a, 3b, 3c, E, M and N genes of FCoV strain FECV 79-1683. Database accession no. Y13921. EMBL, Heidelberg, Germany.

16. Herrewegh, A. A. P. M., H. Vennema, M. C. Horzinek, P. J. M. Rottier, and R. J. de Groot. 1995. The molecular genetics of feline coronaviruses: comparative sequence analysis of the ORF7a/7b transcription unit of different biotypes. Virology 212:622-631.

17. Higgins, D. G., and P. M. Sharp. 1989. Fast and sensitive multiple sequence alignments on a micro computer. Comput. Appl. Biosci. 5:151-153.

18. Hohdatsu, T., S. Okada, Y. Ishizuka, H. Yamada, and H. Koyama. 1992. The prevalence of types I and II feline coronavirus infections in cats. J. Vet. Med. Sci. 54:557-562.

19. Hohdatsu, T., S. Okada, and H. Koyama. 1991. Characterization of monoclonal antibodies against feline infectious peritonitis virus type II and antigenic relationship between feline, porcine, and canine coronaviruses. Arch. Virol. 117:85-95.

20. Hohdatsu, T., T. Sasamoto, S. Okada, and H. Koyama. 1991. Antigenic analysis of feline coronaviruses with monoclonal antibodies (MAbs): preparation of MAbs which discriminate between FIPV strain 79-1146 and FECV strain 79-1683. Vet. Microbiol. 28:13-24.

21. Horsburgh, B. C., I. Brierley, and T. D. Brown. 1992. Analysis of a $9.6 \mathrm{~kb}$ sequence from the $3^{\prime}$ end of canine coronavirus genomic RNA. J. Gen. Virol. 73:2849-2862.

22. Jia, W., K. Karaca, C. R. Parrish, and S. A. Naqi. 1995. A novel variant of infectious bronchitis virus resulting from recombination among three different strains. Arch. Virol. 140:259-271.

23. Keck, J. G., G. K. Matsushima, S. Makino, S. Fleming, D. M. Vannier, S. A Stohlman, and M. M. C. Lai. 1988. In vivo RNA-RNA recombination of coronavirus in mouse brain. J. Virol. 62:1810-1813.

24. Kirkegaard, K., and D. Baltimore. 1986. The mechanism of RNA recombination in poliovirus. Cell 47:433-443.

25. Koolen, M. J. M., M. A. J. Borst, M. C. Horzinek, and W. J. M. Spaan. 1990. Immunogenic peptide comprising a mouse hepatitis virus A59 B-cell epitope and an influenza virus T-cell epitope protects against lethal infection. J. Virol. 64:6270-6273.

26. Kottier, S. A., D. Cavanagh, and P. Britton. 1995. Experimental evidence of recombination in coronavirus infectious bronchitis virus. Virology 213:569580 .

27. Kusters, J. G., E. J. Jager, H. G. M. Niesters, and B. A. M. Zeist. 1990. Sequence evidence for RNA recombination in field isolates of avian coronavirus infectious bronchitis virus. Vaccine 8:605-608.

28. Lai, M. M. C. 1992. RNA recombination in animal and plant viruses. Microbiol. Rev. 56:61-79.

29. Lai, M. M. C. 1996. Recombination in large RNA viruses: coronaviruses. Semin. Virol. 7:381-388

30. Lai, M. M. C., R. C. Baric, S. Makino, J. G. Keck, J. Engbert, J. L. Leibowitz, and S. A. Stohlman. 1985. Recombination between nonsegmented RNA genomes of murine coronaviruses. J. Virol. 56:449-456.

31. Liao, C., and M. M. C. Lai. 1992. RNA recombination in a coronavirus: 
recombination between viral genomic RNA and transfected RNA fragments. J. Virol. 66:6117-6124

32. Luytjes, W. 1995. Coronavirus gene expression: genome organization and protein expression, p. 33-49. In S. G. Siddell (ed.), The Coronaviridae. Plenum Press, New York, N.Y.

33. Makino, S., J. G. Keck, S. A. Stohlman, and M. M. C. Lai. 1986. Highfrequency RNA recombination of murine coronaviruses. J. Virol. 57:729-739.

34. McArdle, F., M. Bennett, R. M. Gaskell, B. Tennant, D. F. Kelly, and C. J. Gaskell. 1990. Canine coronavirus infection in cats; a possible role in feline infectious peritonitis. Adv. Exp. Med. Biol. 276:475-479.

35. McArdle, F., M. Bennett, R. M. Gaskell, B. Tennant, D. F. Kelly, and C. J. Gaskell. 1992. Induction and enhancement of feline infectious peritonitis by canine coronavirus. Am. J. Vet. Res. 53:1500-1506.

36. Motokawa, K., T. Hohdatsu, C. Aizawa, H. Koyama, and H. Hashimoto 1995. Molecular cloning and sequence determination of the peplomer protein gene of feline infectious peritonitis virus type I. Arch. Virol. 140:469 480 .

37. Motokawa, K., T. Hohdatsu, H. Hashimoto, and H. Koyama. 1996. Comparison of the amino acid sequence and phylogenetic analysis of the peplomer, integral membrane and nucleocapsid proteins of feline canine and porcine coronaviruses. Microbiol. Immunol. 40:425-433.

38. Nakanaga, K., K. Yamanouchi, and K. Fujiwara. 1986. Protective effect of monoclonal antibodies on lethal mouse hepatitis virus infection in mice. J. Virol. 59:168-171.

39. Pedersen, N. C., J. W. Black, J. F. Boyle, J. F. Evermann, A. J. McKeirnan, and R. L. Ott. 1984. Pathogenic differences between various feline coronavirus isolates, p. 365-380. In P. J. M. Rottier, B. A. M. Zeijst, W. J. M. Spaan, and M. C. Horzinek (ed.), Molecular biology and pathogenesis of coronaviruses. Plenum Press, New York, N.Y.

40. Rasschaert, D., J. Gelfi, and H. Laude. 1987. Enteric coronavirus TGEV: partial sequence of the genomic RNA, its organization and expression. Biochimie 69:591-600.
41. Siddell, S. G. 1995. The Coronaviridae, p. 1-10. In S. G. Siddell (ed.), The Coronaviridae. Plenum Press, New York, N.Y.

42. Sneath, P. H. A., and R. R. Sokal. 1973. Numerical taxonomy, p. 230-234. W. H. Freeman and Company, San Francisco, Calif.

43. Stoddart, C. A., J. E. Barlough, C. A. Baldwin, and F. W. Scott. 1988. Attempted immunisation of cats against feline infectious peritonitis using canine coronavirus. Res. Vet. Sci. 45:383-388.

44. van der Most, R. G., L. Heijnen, W. J. M. Spaan, and R. J. de Groot. 1992. Homologous RNA recombination allows efficient introduction of site-specific mutations into the genome of coronavirus MHV-A59 via synthetic co-replicating RNAs. Nucleic Acids Res. 20:3375-3381.

44a.Vennema, H. Personal communication.

45. Vennema, H., R. J. de Groot, D. A. Harbour, M. C. Horzinek, and W. J. Spaan. 1991. Primary structure of the membrane and nucleocapsid protein genes of feline infectious peritonitis virus and immunogenicity of recombinant vaccinia viruses in kittens. Virology 181:327-335.

46. Vennema, H., A. Poland, K. Floyd Hawkins, and N. C. Pedersen. 1995. A comparison of the genomes of FECVs and FIPVs and what they tell us about the relationships between feline coronaviruses and their evolution. Feline Pract. 23:40-44.

47. Wang, L., D. Junker, and E. W. Collisson. 1993. Evidence of natural recombination within the S1 gene of infectious bronchitis virus. Virology 192: 710-716.

48. Wesseling, J. G., G. Godeke, V. E. C. J. Schijns, L. Prevec, F. L. Graham, M. C. Horzinek, and P. J. M. Rottier. 1993. Mouse hepatitis virus spike and nucleocapsid proteins expressed by adenovirus vectors protect mice against a lethal infection. J. Gen. Virol. 74:2061-2069.

49. Wesseling, J. G., H. Vennema, G. Godeke, M. C. Horzinek, and P. J. M. Rottier. 1994. Nucleotide sequence and expression of the spike (S) gene of canine coronavirus and comparison with the $\mathrm{S}$ proteins of feline and porcine coronaviruses. J. Gen. Virol. 75:1789-1794. 